\title{
TWO UNUSUAL NEW MYRMICINE ANTS FROM CAMEROON (HYMENOPTERA: FORMICIDAE)
}

\author{
By Roy R. SNELLING ${ }^{1}$
}

\section{INTRODUCTION}

The two following ant species, both previously undescribed, were submitted to me for identification by D. McKey; they were collected during his continuing examination of Afrotropical myrmecophytes. Neither could be keyed to any myrmicine genus known to occur in sub-Saharan Africa in the keys by Bolton (1973) or Hölldobler and Wilson (1990). Samples were sent to Bolton; he concurred that both were undescribed, one in the Afrotropical genus Atopomyrmex Andre (1889) and the second in the nearly cosmopolitan genus Leptothorax Mayr (1855).

Since each of these exhibits peculiarities that render them unkeyable in existing generic keys, it is deemed advisable to describe them. The Afrotropical species in both genera have been recently revised by Bolton $(1981,1982)$.

\section{ATOPOMYRMEX}

Atopomyrmex is a small genus limited to sub-Saharan Africa. Bolton (1981) described the worker characteristics of the genus and differentiated between the two known species of Atopomyrmex, A. mocquerysi André (1889) and A. cryptoceroides Emery (1891).

The following new species is at variance with the generic characterization provided by Bolton, and that characterization must now be modified. In the brief descriptive statements below, the character state as described by Bolton is indicated in parentheses. Despite these numerous departures from Bolton's characterization of Atopomyrmex, the habitus of this new species is certainly that of

This paper is dedicated, with profound respect and admiration, to my colleague Bill Brown. His contributions to the systematics of ants, particularly of the ponerines and dacetines, are an inspiration to all. Thank you, Bill!

${ }^{1}$ Natural History Museum of Los Angeles County, 900 Exposition Boulevard, Los Angeles, Calif. 90007.

Manuscript received 18 August 1992. 
Atopomyrmex. The character states cited below are, without exception, believed to be of specific level value only, though there is no doubt that 50 years ago a new generic name would have been proposed for this ant.

Palpal formula 5,3 in all sizes (4,3). Antenna 9-segmented, with short, stout scape and thickly clavate flagellum (12-segmented, scape slender, flagellum longer and with distinct 3-segmented club). Pronotum hardly marginate at side (bluntly marginate). Promesonotal suture distinct across dorsum in small workers (obsolete in workers of all sizes). Mesonotum not tuberculate in profile (tuberculate) and larger workers without transverse impression at midlength (transverse impression present). Petiole without dorsal spine pair (spines present). Head and body with numerous standing hairs (standing hairs absent except on mouthparts, flagellum, and gastral sterna).

\section{Atopomyrmex calpocalycolus, new species}

Figures 1-5

Diagnosis. - The worker of A. calpocalycolus is immediately separable from its two congeners by the presence of fully erect hairs on the mesosomal dorsum and the absence of dorsal spines on the petiole node. Additional unique features are italicized in the description. The female and male castes are unknown.

Description. - Worker, measurements (mm): HL 1.01-1.74; HW 0.88-1.48; SL 0.49-0.71; PW 0.64-1.03; WL 1.06-2.00; TL 3.88-7.03. Indices: CI 85-87; SI 48-55.

Head distinctly longer than broad in all sizes. Mandible with well-separated fine punctures, interspaces nearly smooth to finely shagreened. Frontal carinae only slightly increasing in relative length and strength with increasing size (Figs. 2, 4). Antennal scrobes poorly defined in all worker sizes. Maximum eye diameter 0.14-0.27 mm, about 0.16-0.17 times head width. Antennal scape stout, ending only slightly above level of eye; flagellum 7-segmented, stoutly and evenly clavate, without differentiated apical club.

Outline of mesosoma as in Figs. 1, 3. Promesonotum curved, mesonotum without conspicuous lateral tubercles. Propodeal 

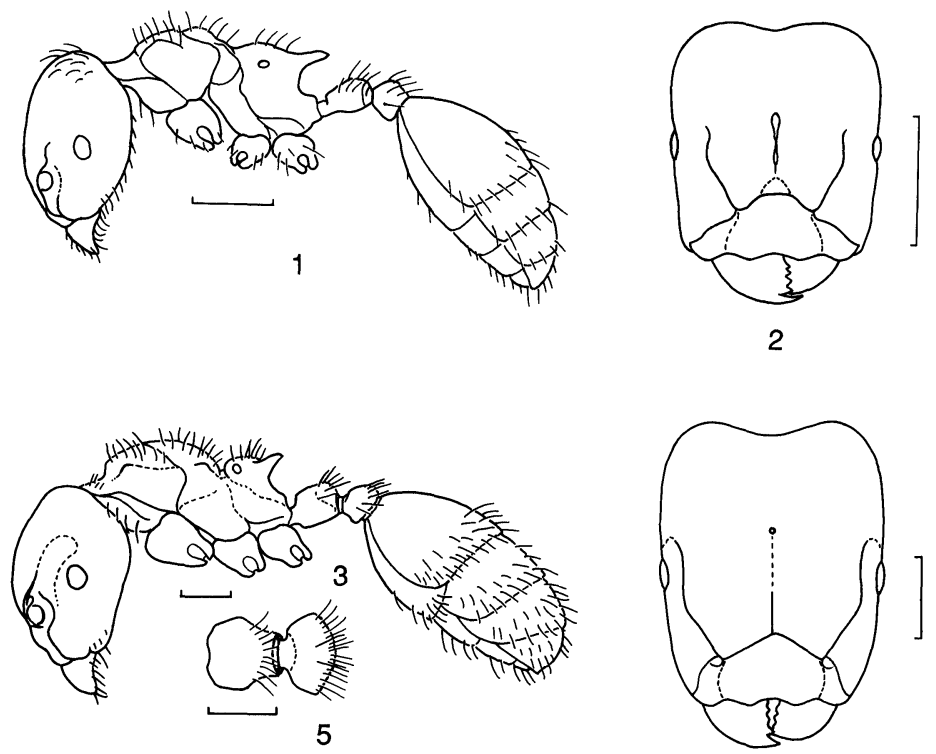

4
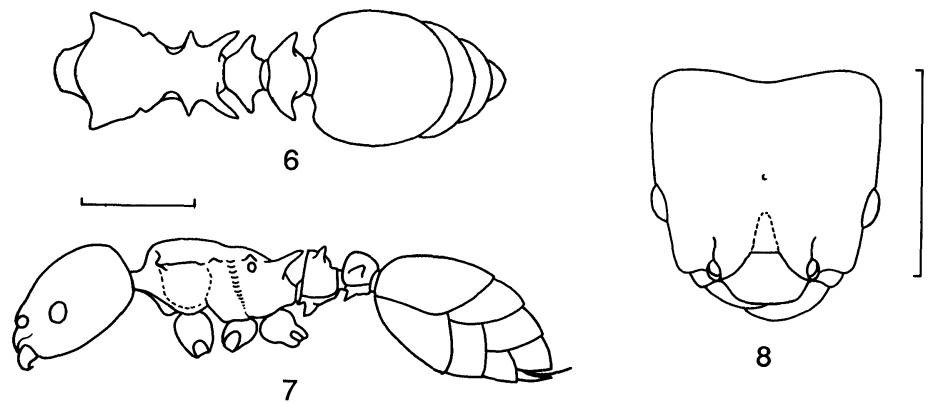

Figures 1-5, Atopomyrmex calpocalycolus: 1, minor worker profile; 2, minor worker head, frontal view; 3, major worker profile; 4, major worker head, frontal view; 5, petiole and postpetiole, dorsal view. Figures 6-8, Leptothorax catalaucoides, worker: 6, meso- and metasoma, dorsal view; 7, head and body, lateral view; 8 , head, frontal view. Scale lines $=0.50 \mathrm{~mm}$. Figures by Tina Ross. 
spines relatively short and thick; propodeal spiracle well basad of base of spine and not visible from above.

Node of petiole (Figs. 1, 3, 5) without dorsal teeth or spines.

Sculpture everywhere very fine; front of head with very fine, close striae and sparse, fine punctures, becoming smooth between punctures on gena and side of vertex. Dorsal surfaces of mesosoma, petiole, and postpetiole dull, densely shagreened and without other obvious sculpture; side of pronotum shiny and punctate below; side of propodeum with shiny, nearly smooth area of variable extent. Gastral terga moderately shiny between ultraminute, subcontiguous, piligerous punctures.

Smallest workers with sparse, erect brownish hairs across vertex and on side of head near dorsolateral corners, larger workers with only 2-4 hairs near dorsolateral corners; dorsum of mesosoma with sparse, erect and suberect golden brownish hairs of variable length; gaster similar along segment margins and on discs of most segments beyond tergum 1. Dorsum of mesosoma with abundant very fine, appressed pubescence; gastral terga with conspicuous appressed pubescence that partially obscures surface.

Color very dark reddish brown in mature specimens, clypeus and adjacent areas of face paler.

Type material. - Worker holotype and 26 paratypes from CAMEROON: Bayenti, north of Nguti, Southwest Province, 26 November 1989, collected by D. McKey from internodes of Calpocalyx sp. Holotype and most paratypes in Natural History Museum of Los Angeles County; paratypes also in Museum of Comparative Zoology and The Natural History Museum, London.

Etymology. - The specific name is derived by combining the name of the host myrmecophyte, Calpocalyx, with the suffix -colus (living in).

Discussion. - since this species is presently known only from the type series there is no way of determining whether or not its relationship to Calpocalyx is an obligate one. If so, then the distribution of the ant will be limited to that of the myrmecophyte.

\section{LEPTOTHORAX}

Bolton (1982) has discussed the numerous generic and subgeneric names that are probably best regarded as synonyms of this large and diverse, nearly cosmopolitan genus. He recognized 11 
species in his treatment of the sub-Saharan fauna. While the number of antennal segments in Leptothorax may be either 11 or 12, all previously recognized sub-Saharan species have 12-segmented antennae. Bolton (1973, and in Hölldobler and Wilson, 1990) utilized this antennal count in the keys to the ant genera of the subSaharan region. Consequently, the species described below, with 11-segmented antennae, cannot be keyed to Leptothorax in either key.

\section{Leptothorax catalaucoides, new species}

Figures 6-8

Diagnosis. - Worker separable from all previously known subSaharan species by the 11-segmented antenna and presence of lateral spines on both petiolar and postpetiolar nodes.

Description. - Worker, measurements $(\mathrm{mm})$ : HL 0.58-0.60; HW 0.54-0.56; SL 0.38; WL 0.65-0.68; TL 1.73-1.85. Indices: CI 93-98; OI 18-20; SI 65-67.

Mandible with fine, strong longitudinal rugulae. Apical clypeal margin evenly convex and concealing basal tooth of closed mandibles; median clypeal carina weak, no stronger than carinae on either side. Frontal carinae virtually absent, merging with general sculpture before attaining level of middle of eyes. Antennal scrobes absent; antenna 11-segmented, scape relatively short and, when laid back along front of head, ending well below margin of vertex, SL about $0.67 \times$ HL. Eye small, greatest diameter about $0.12 \mathrm{~mm}$ and about $0.20 \times \mathrm{HW}$, with about 10 or 11 ommatidia in longest row. With head in full frontal view, sides above eyes subparallel; margin of vertex broadly and shallowly concave, subangulate laterally (Fig. 8).

Pronotal humeri sharply angulate, sides distinctly marginate and convergent behind in dorsal view (Fig. 6). Metanotal area, in profile, broadly and very shallowly concave. Propodeum, in dorsal view, with short subbasal spine on each side and long spine-pair at summit of declivity.

Petiole without anterior peduncle; bluntly rounded subpetiolar process present; node in dorsal view, with long spine on each side; node of postpetiole with much thicker spine on each side (Fig. 7). 
Front and side of head opaque, densely and minutely shagreened between sparse, shallow, obscure foveae, but midline distinctly less sculptured, moderately shiny. Promesonotal dorsum dull, densely shagreened, anteriorly with some short, very weak, more or less longitudinal rugulae; side of mesosoma slightly shiny, especially mesepisternum, surface distinctly, though shallowly, punctulate. Nodes of petiole and postpetiole similar to dorsum of propodeum but slightly shinier. Gastral terga and sterna shiny and smooth except for scattered minute hair pits.

Suberect or erect hairs are short, fine, and inconspicuous, limited to several along ventral margin of mandible and posterior margins of apical gastral segments.

Type material. - Holotype and 16 paratype workers from CAMEROON, Southwest Province: Big Ngwandi, Rumpi Hills, 14-15 November, 1989, collected by D. McKey from internodes of the myrmecophyte, Leonardoxa africana. Holotype and most paratypes in LACM; paratypes also in BMNH and MCZ.

Etymology. - The specific name combines the suffix -oides (resembling) to the name Catalaucus because of the superficial resemblance to ants of that genus.

Discussion. In addition to the characteristics cited in the diagnosis preceding the description this species may be also recognized by the lack of obvious erect hairs on the head and mesosoma, the laterally projecting mesonotum, and the anterior spines on the propodeal dorsum. Because of the laterally subangulate vertex, sharp pronotal humeri, laterally marginate pronotal dorsum, projecting mesonotum and bispinose propodeum, $L$. catalaucoides is very suggestive of the genus Catalaucus.

\section{ACKNOWLEDGMENTS}

Many thanks are due my colleague Barry Bolton, whose profound knowledge of the African myrmecofauna has proven so helpful at various times. Thanks, too, to Doyle McKey, who does have a knack of turning up some interesting ants. I am grateful, also, to Stefan Cover for his comments on an earlier draft of this paper. 


\section{LiTERATURE CITED}

ANDRÉ, E

1899. Hyménoptères nouveaux appartenant au groupe des formicides. Revue Ent. 8: 217-231.

BOLTON, B.

1973. The ant genera of West Africa: a synonymic synopsis with keys. Bull. Brit. Mus. Nat. Hist. (Ent.). 27: 317-368.

1981. A revision of six minor genera of Myrmicinae (Hymenoptera: Formicidae) in the Ethiopian zoogeographical region. Bull. Brit. Mus. Nat. Hist. (Ent.). 43: 245-307.

1982. Afrotropical species of the myrmicine ant genera Cardiocondyla, Leptothorax, Melissotarsus, Messor and Cataulacus (Formicidae). Bull.

EMERY, C. Brit. Mus. Nat. Hist. (Ent.). 45: 307-370.

1891. Voyage de M. Ch. Alluaud dans le territoire d'Assinie (Afrique occidentale) en juillet et aout 1886. Ann. Soc. Ent. France 60: 553-574.

HölLDOBLER, B., AND E. O. WILSON

1990. The Ants. Belknap Press, Harvard Univ., Cambridge, Mass. 773 pp. MAYR, G.

1855. Formicina austriaca. Beschreibung der bisher im osterreichischen Kaiserstaate aufgefundene Ameisen nebst Hinzufugung jener in Deutschland in der Schweiz und in Italien vorkommenden Arten. Verb. zool.-bot. Ver. Wien. 5: 273-478. 

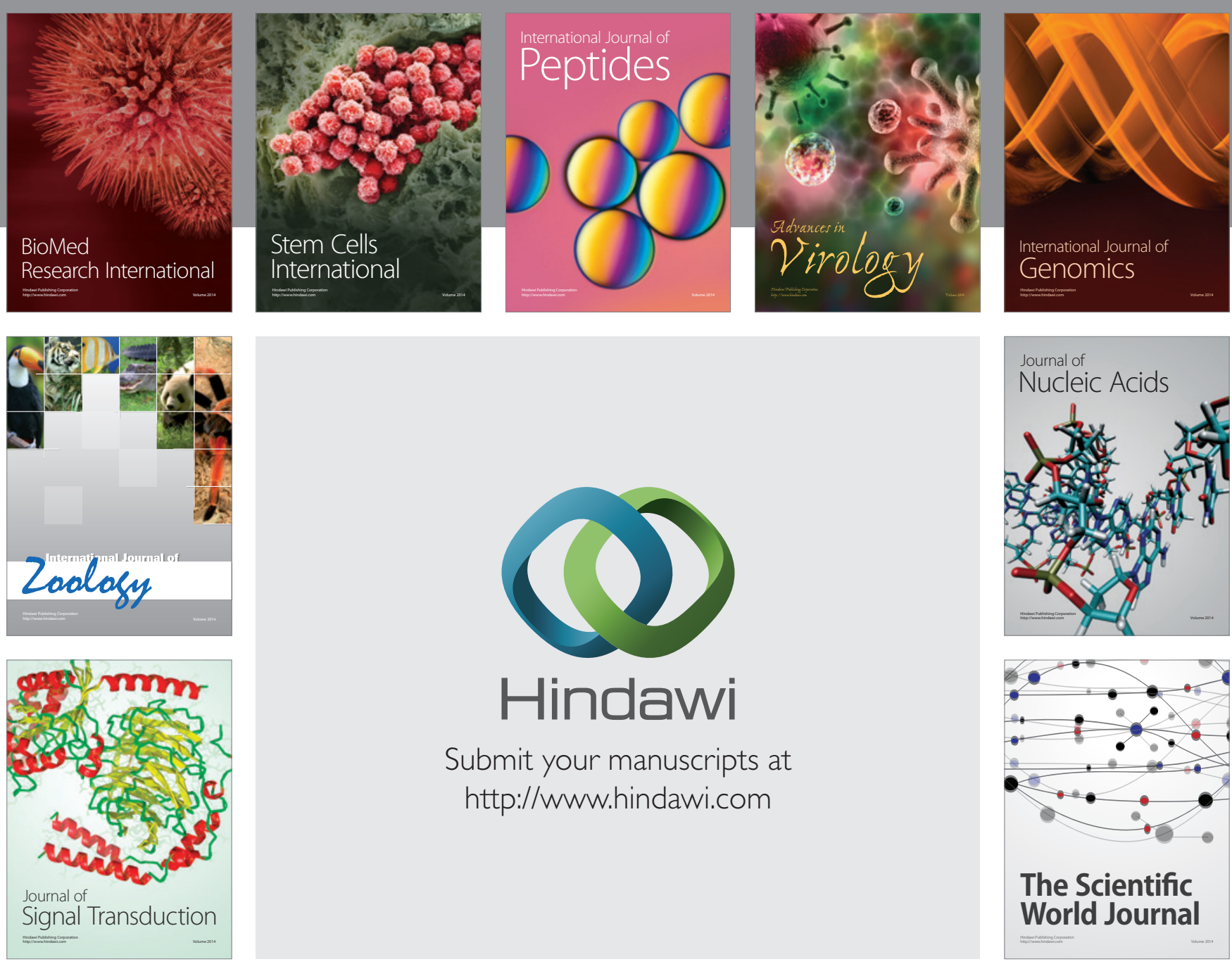

Submit your manuscripts at

http://www.hindawi.com
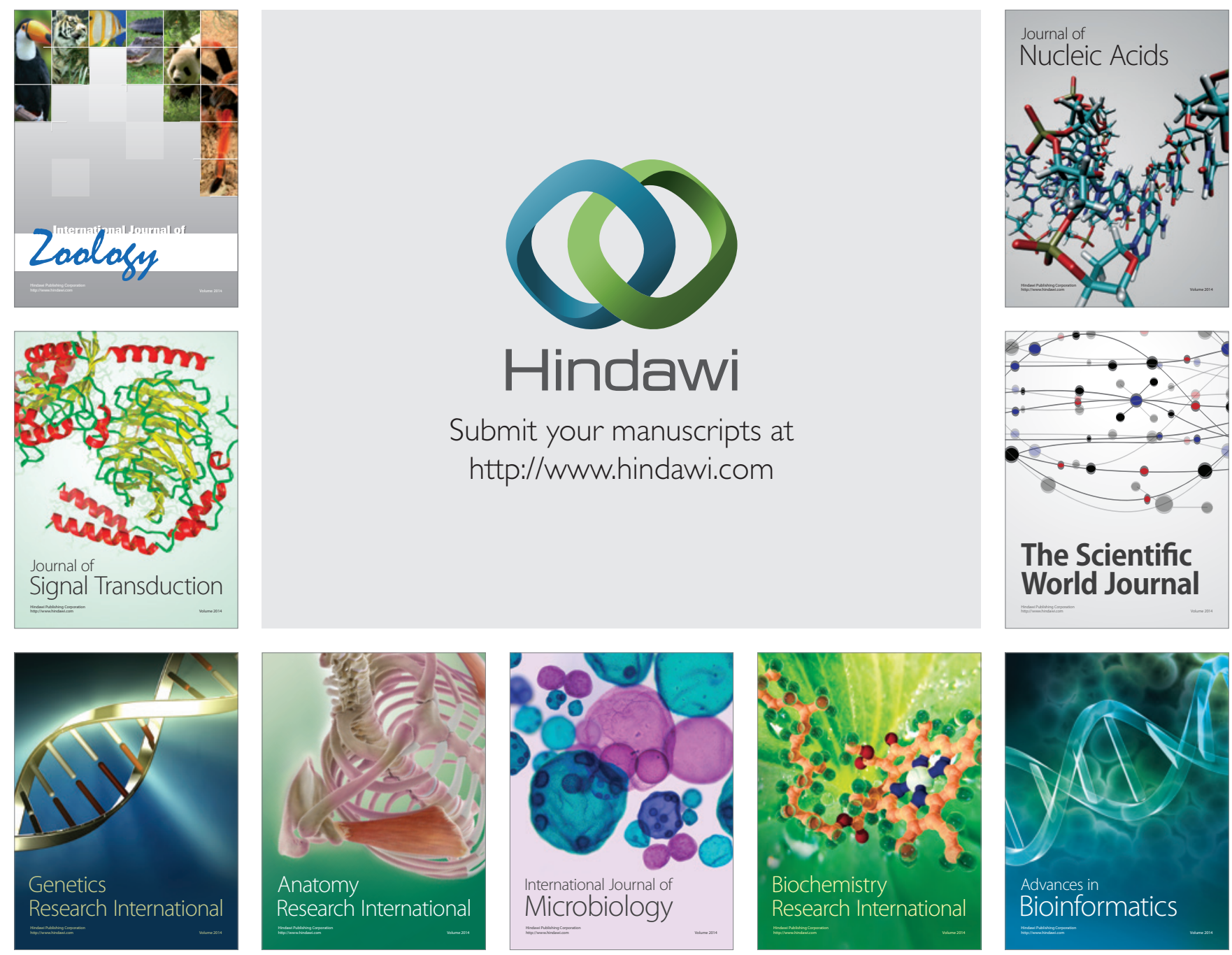

The Scientific World Journal
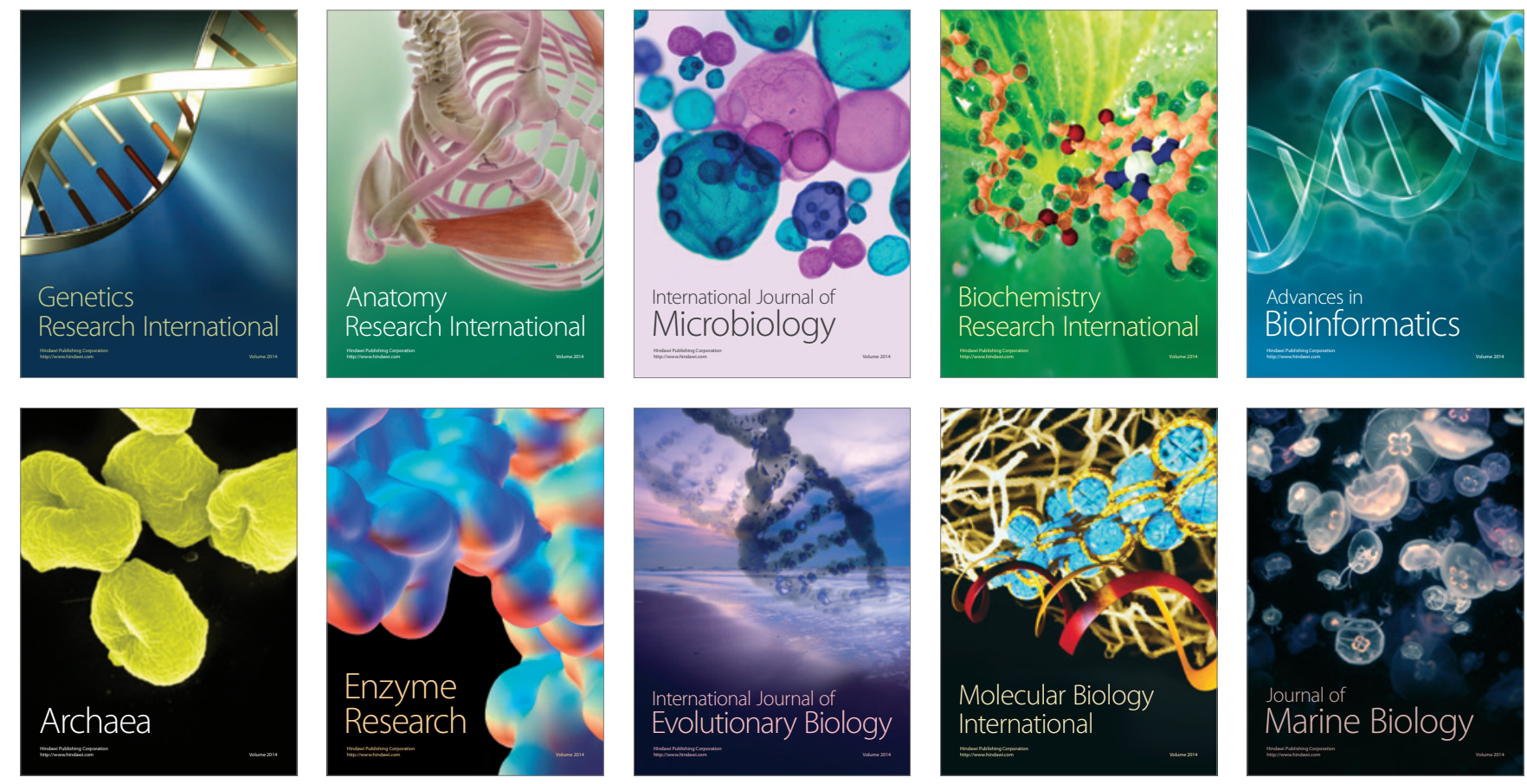